\title{
Effect of the Timing of Surgery on Neurological Recovery for Patients with Incomplete Paraplegia Caused by Metastatic Spinal Cord Compression
}

\author{
Yunpeng Cui (D) \\ Xuedong Shi' \\ Chunwei $\mathrm{Li}^{2}$ \\ Chuan $\mathrm{Mi}^{\mathrm{I}}$ \\ Bing Wang' \\ Yuanxing Pan' \\ Yunfei Lin' \\ 'Department of Orthopaedics, Peking \\ University First Hospital, Beijing, People's \\ Republic of China; ${ }^{2}$ Department of \\ Neurosurgery, Peking University First \\ Hospital, Beijing, People's Republic of \\ China
}

\begin{abstract}
Objective: This study aimed to investigate the effect of timing of surgery on neurological recovery for patients with metastatic spinal cord compression (MSCC).

Methods: According to the timing of surgery, 75 patients with incomplete paraplegia caused by MSCC were assigned to 3 groups: within 3 days (group A), between 4 days and 7 days (group B), and after 7 days (group C). $T$-test, one-way ANOVA, Mann-Whitney $U$-test, and Chi-square test were used to evaluate the difference in the improvement of American Spinal Injury Association Impairment Scale (AIS) and ambulatory status, the incidence of perioperative complications, surgical site infection, and the length of hospital stay between 3 groups.
\end{abstract}

Results: Patients with incomplete paraplegia treated in our department had an average of $17.4 \pm 1.8$ days delayed and most occurred before hospitalization (4.0 \pm 0.4 vs $13.2 \pm 1.8$, $\mathrm{P}<0.001$ ). There was no significant difference in the AIS improvement between patients with different pre-op AIS. The timing of surgery was significantly correlated with AIS improvement (correlation coefficient $=-0.257, \mathrm{P}=0.019$ ). Sub-analysis showed that patients who underwent surgery within 7 days (group A and group B) had significantly better AIS improvement compared with group $\mathrm{C}$ (improved at least 1 grade, $\mathrm{P}=0.043$; improved more than 1 grade, $\mathrm{P}=0.039$ ) and the surgery timing was more important for patients with AIS $\mathrm{B}$ and $\mathrm{C}$. The timing of surgery was significantly correlated with the length of hospital stay (correlation coefficient $=0.335, \mathrm{P}=0.003$ ). Patients of group $\mathrm{C}$ had the longest length of hospital stay $(\mathrm{P}=0.002)$. The incidence of perioperative complications and surgical site infection did not differ significantly between the 3 groups.

Conclusion: Delay surgery was common in incomplete paraplegia patients with MSCC. Patients with AIS $\mathrm{B}$ and $\mathrm{C}$ who underwent surgery within 7 days had better AIS improvement.

Keywords: timing of surgery, metastatic spinal cord compression, incomplete paraplegia, neurologic function

\section{Introduction}

Metastatic spinal cord compression (MSCC) is one of the most severe complications for patients with cancer. The number of patients with MSCC has remarkably increased in recent years. ${ }^{1,2}$ Treatment of MSCC is dependent upon global performance status, expected survival, neurological and mechanical factors of the patients. ${ }^{3-5}$ Spinal cord injury caused by MSCC is a major challenge for spinal surgeons. The timing of surgery is considered to be a key factor affecting neurological recovery. For patients with acute complete paraplegia caused by MSCC or trauma, surgery should be performed as soon as possible. ${ }^{6-9}$ However, it is not clear
Correspondence: Xuedong Shi University First Hospital, No. 7 Xishiku Street, Xicheng District, Beijing, 100032, People's Republic of China Tel +86 10-83575660

Email pku_ortho@I63.com 
when the surgery should be performed for patients with incomplete paraplegia caused by MSCC.

More evidence is needed to confirm the relationship between the timing of surgery and neurological recovery for patients with incomplete paraplegia caused by MSCC. Most studies have only focused on patients' survival or just report the results of the neurological outcomes. ${ }^{10,11}$ Relatively few studies investigated neurological prognostic factors for patients with MSCC. ${ }^{12-15}$ These studies had either small sample size or enrolled patients with lumbar and sacral metastases. Besides, there was no independent analysis of paraplegia and incomplete paraplegia among these studies. Fürstenberg et al just reviewed 35 patients. ${ }^{12}$ Although a total of 153 patients were included in the study performed by Quraishi et al, 30 patients with lumbar and sacral metastases without spinal cord were also included. ${ }^{14}$ These studies' results cannot truly reflect the relationship between the timing of surgery and the neurological recovery of patients with incomplete paraplegia caused by MSCC.

We performed this study to investigate the effect of the timing of surgery on neurological recovery for patients with incomplete paraplegia caused by MSCC. Meanwhile, we evaluate its impact on patients' perioperative complications, wound infections, and the length of hospital stay.

\section{Materials and Methods Study Design and Selection Criteria}

This study was a single-centered retrospective, nonrandomized cohort study of patients with spinal metastases who performed decompression surgery from November 2010 to September 2017. A total of 211 patients were included as our initial cases. We excluded those patients with incomplete data (4), lumbar spine metastases (49), normal spinal cord function and ambulatory status (78), complete paraplegia (3), and spinal cord function deteriorated within 2 weeks after surgery due to tumor progression (2). At least, 75 patients with incomplete spinal cord injury were included in this study. They were assigned to 3 groups according to the surgery timing (counted from the onset of the symptom: weakness or numbness): group A comprised patients who underwent surgery within 3 days; group B comprised patients who underwent surgery between 4 and 7 days, and group C comprised patients who underwent surgery after 7 days. Only the first round was analyzed for patients who underwent multiple-round surgery at the same site due to tumor recurrence.

All patients underwent a physical examination. X-ray and Magnetic Resonance Imaging (MRI) were performed to confirm the location of the lesion. Their blood samples were taken before surgery. The choice of surgical treatment mainly depends on the patients' Tokuhashi score. Usually, patients with a life expectancy of less than 6 months (Tokuhashi score $>8$ ) received palliative treatment, while other patients received surgical treatment. However, with the development of targeted therapy, the prognosis of some patients has been improved, such as patients with adenocarcinoma of lung and these patients (Tokuhashi score $<8$ ) tend to receive surgical treatment. For patients with a life expectancy of more than 12 months, a total or subtotal spondylectomy was carried out, while other patients received decompression surgery. Tumour debulked at the same time when patients underwent decompression surgery. All the tumors on the dorsal and bilateral sides of dura were removed. Tumors on the ventral sides of dura were partially removed and the space between tumor and dura should be kept at least $1 \mathrm{~mm}$ to ensure that the spinal cord compression was completely relieved. The surgery option was determined by multidisciplinary cooperation, composing of an experienced neuroradiologist, a spinal tumor surgeon, and an oncologist. Our institute's research ethics boards approved the study protocol and required neither patient approval nor informed consent for review of patients' images and medical records. Moreover, this study was conducted in accordance with the declaration of Helsinki. The flow of patient enrolment is shown in Figure 1.

\section{Data Collection}

Patients' characteristics, including demographic information, comorbidities (cardiovascular and respiratory system), primary tumor pathology, ambulatory status, and neurological function according to American Spinal Injury Association Impairment Scale (AIS) recorded preop and 2 weeks post-op, Karnofsky score, Eastern Cooperative Oncology Group (ECOG), and Tokuhashi score were carefully extracted from their electronic medical records. Surgery related data such as the location (cervical; upper thoracic: T1-T6; lower thoracic: T7-T12) and the number of decompression segment, the grade of epidural compression (Bilsky), perioperative complications, surgical site infection, and the length of hospital stay were also collected. 


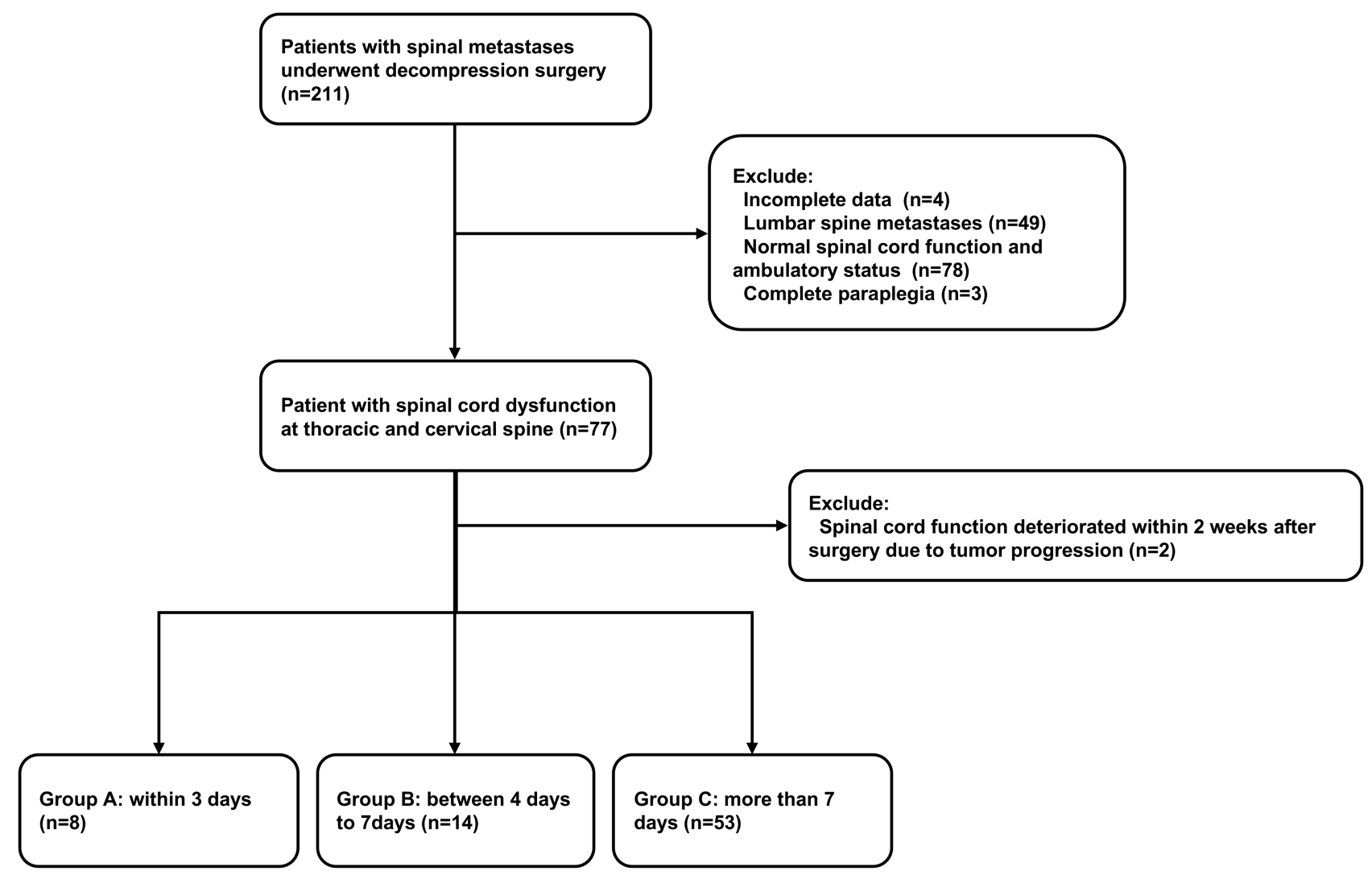

Figure I Flowchart of patients inclusion.

\section{Treatment Method}

Surgery was performed via the median posterior approach by three experienced spinal tumor surgeons under general anesthesia. Laminectomy or corpectomy combined with or without bone cement was performed based on the location of the tumor. Patients were given methylprednisolone $500 \mathrm{mg}$ on the day of surgery and then gradually reduced to stop 4 days after surgery. Patients received adjuvant radiotherapy postoperatively as required.

\section{Measurement of Outcomes}

Five clinical outcome measures were included in this study: 1) spinal cord function, 2) ambulatory status, 3) perioperative complications, 4) surgical site infection, 5) the length of hospital stay. The change in AIS evaluated spinal cord functional outcomes at 2 weeks after surgery. Perioperative complications included surgical or postoperative complications, such as dural sac injury and respiratory system complications.

\section{Statistical Analysis}

Quantitative variables were presented as mean (standard deviation) when they were in a normal distribution and median (range) when they were not. Categorical variables are presented as frequencies and constituent ratios. Independent $t$-test, one-way ANOVA, and Mann-Whitney $U$-test were used to detect the quantitative variables' difference. The differences among the categorical variables were analyzed using the Fisher's exact test or Pearson Chi-square test. The relationship between surgery timing and outcome measures was evaluated using the Kendall tau rank and Spearman correlation analysis. All tests were 2-sides. Delete cases with missing values during the statistical process. A p-value $<0.05$ was considered statistically significant. All statistical analyses were performed with the IBM SPSS Statistics 25 (IBM Corporation, Armonk, NY.).

\section{Results}

\section{Sample Baseline Characteristics}

In total, 75 patients were enrolled in the study. There are 8 patients in group A, 14 in group B, and 53 in group C. Patients' baseline characteristics are shown in Table 1. The demographic, primary tumor, Tokuhashi score, compression grade of the spinal cord, location, and the number of decompression segments did not differ significantly between 3 groups. The sub-analysis showed group $\mathrm{C}$ had 
Table I Comparison of Patients' Baseline Characteristics

\begin{tabular}{|c|c|c|c|c|c|}
\hline Characteristic & $\begin{array}{l}\text { Group A: } \\
n=8\end{array}$ & $\begin{array}{l}\text { Group B: } \\
n=14\end{array}$ & $\begin{array}{l}\text { Group C: } \\
n=53\end{array}$ & $\begin{array}{l}\text { P value: Between } 3 \\
\text { Groups }\end{array}$ & $\begin{array}{l}\text { P value: } \\
A+B \text { vs } C\end{array}$ \\
\hline Age & $60 \pm 4$ & $63 \pm 3$ & $61 \pm 2$ & 0.799 & 0.660 \\
\hline \multicolumn{6}{|l|}{ Gender } \\
\hline $\begin{array}{l}\text { Female } \\
\text { Male }\end{array}$ & $\begin{array}{l}5 \\
3\end{array}$ & $\begin{array}{l}11 \\
3\end{array}$ & $\begin{array}{l}40 \\
13\end{array}$ & 0.685 & 0.779 \\
\hline \multicolumn{6}{|l|}{ Number of comorbidities } \\
\hline $\begin{array}{l}0 \\
1 \\
2\end{array}$ & $\begin{array}{l}5 \\
3 \\
0\end{array}$ & $\begin{array}{l}6 \\
7 \\
1\end{array}$ & $\begin{array}{l}27 \\
12 \\
14\end{array}$ & 0.122 & 0.039 \\
\hline Karnofsky score pre-op & $40(40-40)$ & $40(40-60)$ & $50(40-60)$ & 0.018 & 0.012 \\
\hline ECOG & $4(4-4)$ & $4(3-4)$ & $3(2-4)$ & 0.009 & 0.005 \\
\hline SINS & $8(8-8)$ & $7(7-10)$ & $8(7-10)$ & 0.483 & 0.483 \\
\hline \multicolumn{6}{|l|}{ Tumor pathology } \\
\hline $\begin{array}{l}\text { Renal } \\
\text { Breast } \\
\text { Lung } \\
\text { Ovarian } \\
\text { Liver } \\
\text { Prostate } \\
\text { Multiple myeloma } \\
\text { Lymphoma } \\
\text { Mucinous adenocarcinoma of } \\
\text { scalp } \\
\text { Colorectal } \\
\text { Malignant thymoma } \\
\text { Angiosarcoma }\end{array}$ & $\begin{array}{l}1 \\
0 \\
3 \\
0 \\
0 \\
1 \\
0 \\
2 \\
1 \\
0 \\
0 \\
0\end{array}$ & $\begin{array}{l}3 \\
1 \\
3 \\
0 \\
0 \\
4 \\
2 \\
0 \\
0 \\
1 \\
0 \\
0\end{array}$ & $\begin{array}{l}10 \\
3 \\
9 \\
1 \\
6 \\
11 \\
7 \\
3 \\
0 \\
1 \\
1 \\
1\end{array}$ & 0.430 & 0.718 \\
\hline Tokuhashi score & $6(3-10)$ & $7(2-11)$ & $7(2-10)$ & 0.532 & 0.331 \\
\hline \multicolumn{6}{|l|}{ Compression grade (Bilsky) } \\
\hline $\begin{array}{l}1 \\
2 \\
3\end{array}$ & $\begin{array}{l}0 \\
0 \\
8\end{array}$ & $\begin{array}{l}1 \\
1 \\
11\end{array}$ & $\begin{array}{l}2 \\
7 \\
37\end{array}$ & 0.638 & 0.472 \\
\hline \multicolumn{6}{|l|}{ Location of the lesion } \\
\hline $\begin{array}{l}\text { Cervical } \\
\text { Upper thoracic } \\
\text { Lower thoracic }\end{array}$ & $\begin{array}{l}0 \\
3 \\
5\end{array}$ & $\begin{array}{l}1 \\
8 \\
5\end{array}$ & $\begin{array}{l}5 \\
29 \\
19\end{array}$ & 0.638 & 0.638 \\
\hline \multicolumn{6}{|c|}{ Number of decompression segments } \\
\hline $\begin{array}{l}\text { Single } \\
\text { Multiple }\end{array}$ & $\begin{array}{l}3 \\
5\end{array}$ & $\begin{array}{l}7 \\
7\end{array}$ & $\begin{array}{l}17 \\
36\end{array}$ & 0.460 & 0.272 \\
\hline \multicolumn{6}{|c|}{ Time delayed from onset of the symptom (day) } \\
\hline $\begin{array}{l}\text { Before Hospitalization } \\
\text { After Hospitalization }\end{array}$ & $\begin{array}{l}0.9 \pm 0.2 \\
1.8 \pm 0.3\end{array}$ & $\begin{array}{l}3.9 \pm 0.5 \\
2.1 \pm 0.4\end{array}$ & $\begin{array}{l}17.5 \pm 2.2 \\
4.9 \pm 0.5\end{array}$ & $\begin{array}{l}<0.001 \\
0.002\end{array}$ & $\begin{array}{l}<0.001 \\
<0.001\end{array}$ \\
\hline
\end{tabular}


Table 2 Comparison of Clinical Outcome Measures

\begin{tabular}{|c|c|c|c|c|c|}
\hline Characteristic & Group A: $n=8$ & Group B: $n=14$ & Group C: $n=53$ & $\begin{array}{l}\text { P value: Between } \\
3 \text { Groups }\end{array}$ & $\begin{array}{l}\text { P value: } \\
A+B \text { vs } C\end{array}$ \\
\hline \multicolumn{6}{|l|}{ AIS pre-op (and post-op) } \\
\hline B & $3(1)$ & $6(1)$ & $3(1)$ & \multirow{4}{*}{$<0.001(0.544)$} & \multirow{4}{*}{$<0.001(0.254)$} \\
\hline $\mathrm{C}$ & $4(2)$ & $2(3)$ & $11(6)$ & & \\
\hline$D$ & I (4) & $6(6)$ & $39(30)$ & & \\
\hline $\mathrm{E}$ & $0(1)$ & $0(4)$ & $0(16)$ & & \\
\hline Improvement at least I grade & 6 & 10 & 25 & 0.127 & 0.043 \\
\hline Improvement more than I grade & 1 & 2 & 1 & 0.117 & 0.039 \\
\hline \multicolumn{6}{|l|}{ AIS improvement } \\
\hline Patients with AIS B and C & 6 & 7 & 9 & 0.431 & 0.159 \\
\hline Patients with AIS D & 0 & 3 & 16 & 0.640 & 0.928 \\
\hline \multicolumn{6}{|l|}{ Ambulatory status pre- op (and post-op) } \\
\hline Nonambulatory & $8(6)$ & $13(9)$ & $44(20)$ & & \\
\hline Ambulatory with assistance & $0(2)$ & I (4) & $9(27)$ & $0.316(0.181)$ & $0.149(0.054)$ \\
\hline Ambulatory & $0(0)$ & $0(1)$ & $0(6)$ & & \\
\hline Improvement & 2 & 5 & 29 & 0.174 & 0.071 \\
\hline \multicolumn{6}{|l|}{ Perioperative complications } \\
\hline With & 0 & 1 & 9 & 0.316 & 0.149 \\
\hline Without & 8 & 13 & 44 & 0.316 & 0.147 \\
\hline \multicolumn{6}{|l|}{ Surgical site infection } \\
\hline With & 0 & I & 3 & 0759 & 0845 \\
\hline Without & 8 & 13 & 50 & 0.159 & 0.845 \\
\hline The length of post-op hospital stays & $13.5(6-44)$ & $11.5(5-66)$ & $16(7-61)$ & 0.051 & 0.019 \\
\hline The length of hospital stays & $15(8-47)$ & $14(10-68)$ & $22(8-64)$ & 0.007 & 0.002 \\
\hline
\end{tabular}

significantly more comorbidity $(\mathrm{P}=0.039)$, higher Karnofsky score $(\mathrm{P}=0.012)$, and ECOG $(\mathrm{P}=0.005)$ compared with group $\mathrm{A}$ and $\mathrm{B}$. Patients with incomplete paraplegia treated in our department had an average of 17.4 \pm 1.8 days delayed and most occurred before hospitalization ( $4.0 \pm 0.4$ vs $13.2 \pm 1.8, \mathrm{P}<0.001)$. Patients in group $\mathrm{C}$ had significantly more time delayed before and after hospitalization compared with group $\mathrm{A}$ and $\mathrm{B}(\mathrm{P}<0.001)$.

\section{American Spinal Injury Association Impairment Scale (AIS) and Ambulatory \\ Status}

Group C had significantly more patients with AIS at grade $\mathrm{D}(\mathrm{P}<0.001)$. The improvement of AIS and ambulatory status did not differ significantly between the three groups (Table 2, Figures 2 and 3). However, surgery timing was significantly negatively correlated with AIS improvement (Correlation coefficient $=-0.257, \mathrm{P}=0.019$ ) (Table 3). The sub-analysis showed that group $\mathrm{C}$ had a significantly better AIS improvement (at least 1 grade, $\mathrm{P}=0.043$; more than 1 grade, $\mathrm{P}=0.039$ ) compared with group $\mathrm{A}$ and $\mathrm{B}$ (Table 2, Figures 2 and 3). The analysis of the patients with different pre-op AIS grade showed that the surgery timing was more important for patients with AIS B and C, and did not even reach statistical significance (Table 3 ). There was no significant difference in the AIS improvement between patients with different pre-op AIS (Table 4).

\section{Perioperative Complications, Surgical Site Infection, and the Length of Hospital Stay} There was no significant difference in the incidence of perioperative complication and surgical site infection between 3 


\begin{tabular}{|c|c|c|c|c|c|c|c|}
\hline \multirow{2}{*}{$\begin{array}{l}\text { A Pre-op } \\
\text { AIS }\end{array}$} & \multirow{2}{*}{$\begin{array}{l}\text { Number of } \\
\text { patients }\end{array}$} & \multicolumn{5}{|c|}{ Post-op AIS } & \multirow[b]{2}{*}{ Group A } \\
\hline & & $A$ & $B$ & $\mathrm{C}$ & $\mathrm{D}$ & $E$ & \\
\hline $\mathrm{B}$ & 3 & 0 & 1 & 2 & 0 & 0 & Improved \\
\hline $\mathrm{C}$ & 4 & 0 & $\overline{0}$ & 0 & 3 & 1 & No change \\
\hline$D$ & 1 & 0 & 0 & 0 & 1 & 0 & Worsen \\
\hline
\end{tabular}

B Pre-op Number of $\quad$ Post-op AIS

\begin{tabular}{l|l|l|l|l|l|l|l}
\cline { 3 - 7 } AIS & patients & A & B & C & D & E & Group B \\
\hline B & 6 & 0 & 1 & 3 & 1 & 1 & Improved \\
\hline C & 2 & 0 & 0 & 0 & 2 & 0 & No change \\
\hline D & 6 & 0 & 0 & 0 & 3 & 3 & Worsen \\
\hline
\end{tabular}

C Pre-op Number of $\quad$ Post-op AIS

\begin{tabular}{|l|l|l|l|l|l|l|l}
\cline { 3 - 7 } AIS & patients & A & B & C & D & E & Group C \\
\cline { 1 - 7 } B & 3 & 0 & 1 & 1 & 1 & 0 & Improved \\
\hline C & 11 & 0 & 0 & 4 & 7 & 0 & No change \\
\hline D & 39 & 0 & 0 & 1 & 22 & 16 & Worsen \\
\hline
\end{tabular}

D Pre-op Number of $\quad$ Post-op AIS

\begin{tabular}{|l|l|l|l|l|l|l|l|}
\cline { 3 - 7 } AIS & patients & A & B & C & D & E & Group A+B \\
\hline B & 9 & 0 & 2 & 5 & 1 & 1 & Improved \\
\hline C & 6 & 0 & 0 & 0 & 5 & 1 & No change \\
\hline D & 7 & 0 & 0 & 0 & 4 & 3 & Worsen \\
\hline
\end{tabular}

Figure 2 Change of American Spinal Injury Association Impairment Scale (AIS) 2 weeks after surgery between 3 groups, as indicated by co-plotting the postoperative AIS against the preoperative AIS. (A), group A; (B), group B; (C), group C. (D), group A+B.

groups (Table 2, Figure 3). The surgery timing (days) was significantly positively correlated with the length of hospital stay (Correlation coefficient $=0.355, \mathrm{P}=0.003$ ) $($ Table 3 ). The sub-analysis showed that group $\mathrm{C}$ had a significantly longer length of total hospital stays and post-op hospital stays than group $\mathrm{A}$ and $\mathrm{B}(\mathrm{P}=0.002, \mathrm{P}=0.019)$ (Table 2). 
American Spinal Injury Association

A

Impairment Scale (AIS)

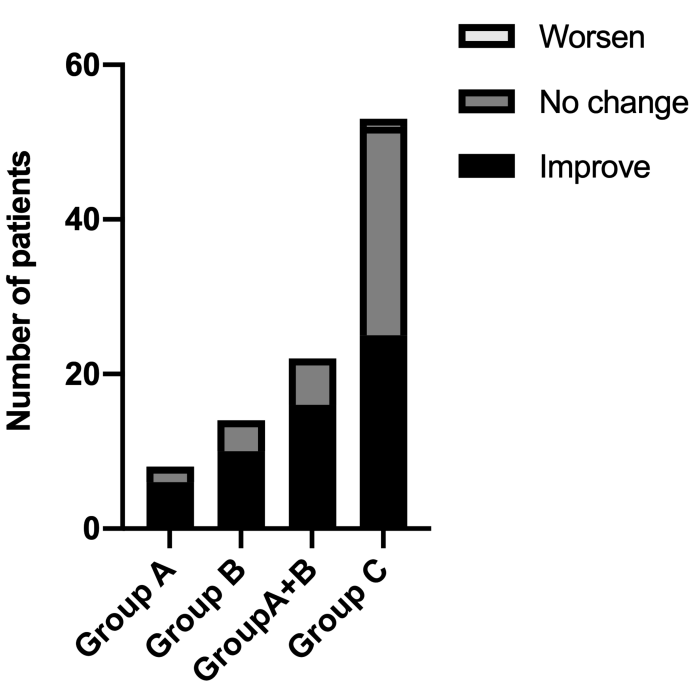

C

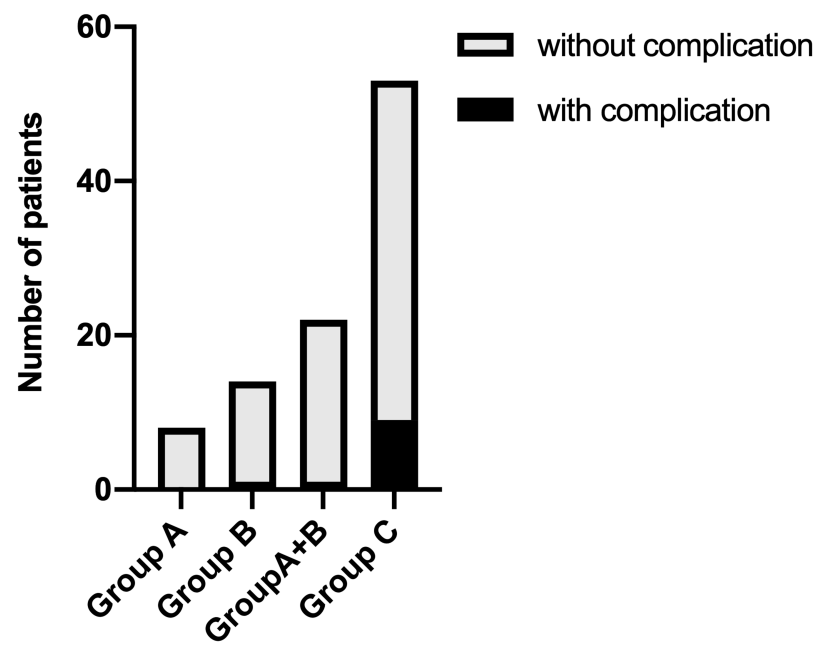

Ambulatory

B

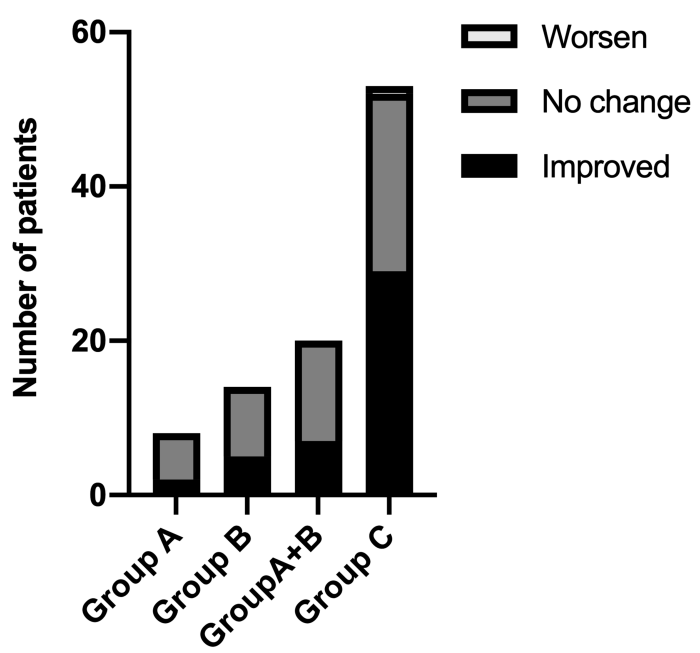

D Surgical site infection

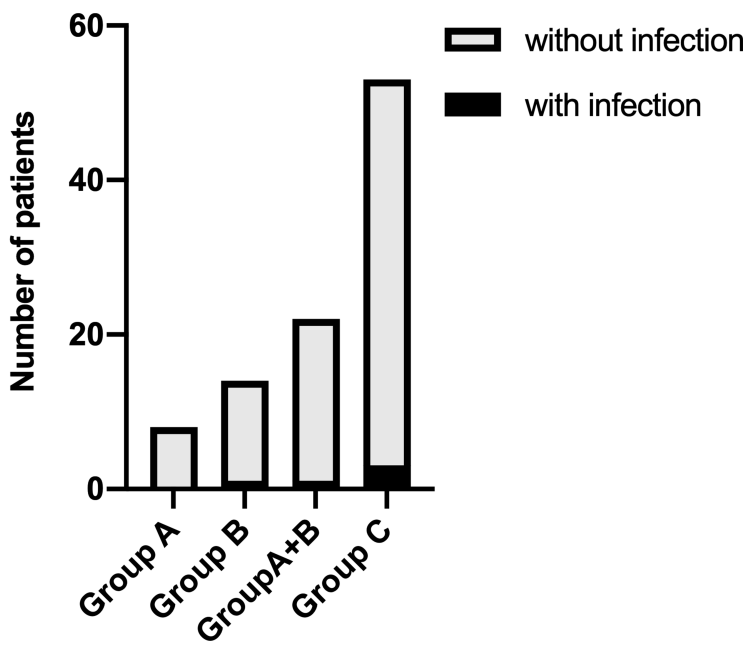

Figure 3 Clinical outcomes of patients in 3 groups. (A), American Spinal Injury Association Impairment Scale (AIS); (B), ambulatory; (C), perioperative complications, (D), surgical site infection.

\section{Discussion}

Although several studies had investigated the prognostic factors of the spinal cord's neurological recovery for patients with MSCC, the present study, including a relatively large number of patients, clearly exclude patients with lumbar $^{10,12,14,15}$ or sacrum ${ }^{14}$ spine and only focuses on patients with incomplete paraplegia.

The study of Fürstenberg et al and Quraishi et al showed that patients with MSCC and neurological deficit underwent surgery within 48 hours to recover better. ${ }^{12,14}$ However, the

Table 3 Relationship Between Timing of Decompression Surgery and Outcome Measures

\begin{tabular}{|l|l|l|l|l|l|}
\hline & $\begin{array}{l}\text { Changes in } \\
\text { AIS }\end{array}$ & $\begin{array}{l}\text { Changes in } \\
\text { Ambulatory }\end{array}$ & Complications & $\begin{array}{l}\text { Surgical Site } \\
\text { Infection }\end{array}$ & $\begin{array}{l}\text { The Length of Hospital } \\
\text { Stays }\end{array}$ \\
\hline $\begin{array}{l}\text { Correlation coefficient } \\
P \text { value }\end{array}$ & $-0.257^{\mathrm{k}}$ & $0.200^{\mathrm{k}}$ & $0.168^{\mathrm{k}}$ & $0.035^{\mathrm{k}}$ & $0.335^{\mathrm{s}}$ \\
& 0.019 & 0.070 & 0.136 & 0.757 & 0.003 \\
\hline
\end{tabular}

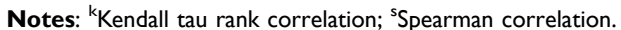


Table 4 Comparison of AIS Improvement of Patients with Different Pre-Op AIS

\begin{tabular}{|l|l|l|l|}
\hline Characteristic & Improved & Not Improved & P value: \\
\hline \multicolumn{2}{|l|}{ Group A } & 1 & 0.250 \\
\hline $\begin{array}{l}\text { ASIA B and C } \\
\text { ASIA D }\end{array}$ & $\begin{array}{l}6 \\
0\end{array}$ & 1 & \\
\hline Group B & 1 & 0.245 \\
\hline $\begin{array}{l}\text { ASIA B and C } \\
\text { ASIA D }\end{array}$ & 7 & 3 & \\
\hline $\begin{array}{l}\text { Group A+B } \\
\text { ASIA B and C }\end{array}$ & 12 & 2 & 0.120 \\
\hline ASIA D & 3 & 4 & \\
\hline Group C & 10 & 5 & 0.131 \\
\hline \multicolumn{2}{|l|}{ ASIA B and C } \\
ASIA D & 16 & 23 & \\
\hline
\end{tabular}

treatment for patients with MSCC was usually delayed. Inadequate understanding of specific symptoms at an early stage and poor general condition in patients with advanced cancer often prevents patients from getting adequate treatment within 48 hours. Husband et al enrolled 301 patients with MSCC. The results showed that only $33 \%$ of patients could walk while receiving treatment, and only $53 \%$ of patients had no catheter placed. These patients had back pain for a median of 2 months before diagnosis, and there was an average 10 days delay from the onset of neurological symptoms to the start of treatment ( 3 days for patients, 3 days for general practitioners, 4 days for regional hospitals). ${ }^{16}$ Similar results could be found in the study of Crnalic et al. ${ }^{13,17}$

The mechanism of spinal cord injury can be divided into primary and secondary injuries. The primary injury appears immediately after the damage, mainly due to tissue destruction, while the secondary injury is caused by a series of complicated pathophysiological processes, including edema, demyelination, apoptosis of nerve cells, scar formation, etc. ${ }^{18}$ Spinal cord edema appears within a few hours after injury and reaches its maximum degree between 3 and 6 days after injury, accompanied by demyelination. For patients with complete paraplegia, spinal cord injury rapidly progressed. When the edema began to recover, the damaged tissue was gradually replaced by central hemorrhage and necrosis, which are more likely to be irreversible. ${ }^{19}$ Unlike complete paraplegia, incomplete paraplegia caused by MSCC usually progresses slowly, and neurological function is more likely to be compensated and reversible. ${ }^{8,20}$ Park et al showed that although Bilsky's compression grade was at 2 or 3, some patients with MSCC still had no signs of neurological deficit. ${ }^{11}$ So, it was reasonable to restrict more "cut-off value (2 days)" for previous studies, including patients with complete paraplegia. ${ }^{12,14}$ However, patients with spinal metastasis at the lumbar and sacrum might affect the validity of their results.

These findings encourage us to conduct a thorough analysis of our database of patients with MSCC and incomplete paraplegia. Patients with incomplete paraplegia treated in our department had an average of $17.4 \pm 1.8$ days delayed. We classify our retrospective cohort into different groups depending on the surgery timing. Patients in group $\mathrm{C}$ had more comorbidities, less Karnofsky score and ECOG, and need more time to complete the preoperative preparations. Most time delayed occurred before hospitalization and the result was consistent with previous results. ${ }^{10,15,16}$ The results of the present study showed that the surgery timing was negatively correlated with AIS improvement. However, our results differed from the previous study at the "cut-off value (7 days vs 2 days)" performed by Fürstenberg et al and Quraishi et al. ${ }^{12,14}$

In our study, group $\mathrm{C}$ had more patients with AIS at grade D. A similar situation appeared in Quraishi et al's report. ${ }^{14}$ This condition explained why patients' ambulatory status in group $\mathrm{C}$ improved best in our study, although did not reach the statistical level. On the other hand, the more patients who were ASIA D with multi-comorbidities in group $\mathrm{C}$, meaning they did not have as much neurological deficit and had less capacity to improve, might skew the results. We analyzed the AIS improvement in patients with different pre-op AIS grades. There was a tendency for patients with ASIA D to improve poorly compared with patients with ASIA B and C. In addition, our results showed that the surgery timing was more important for patients with AIS B and C compared with patients with AIS D. In the following study, we will expand the sample size and analyze patients with different AIS grades separately. Other than preoperative AIS grades, ambulatory status before surgery, the time of developing motor deficits and the quality of decompression also affected the ambulatory recovery. ${ }^{11,21,22}$

Yousefifard et al and Bourassa-Moreau et al reported that the incidence of complications after early surgery was significantly lower than that of delayed surgery for patients with acute traumatic spinal cord injury. $7,9,23$ Similar to Quraishi et al's study, ${ }^{14}$ perioperative complications and surgical site infections did not differ between 3 groups in our study. Based on the results of the present study, although delayed surgery was safe in terms of 
perioperative complications and surgical site infection, the surgery timing had a positive correlation with the length of hospital stay and a negative correlation with the AIS improvement. Patients in group $\mathrm{C}$ had the longest length of hospital stays, including pre-op and post-op hospital stays. This result might be related to the more comorbidity of patients in group $\mathrm{C}$. These patients needed more time for the optimization of their comorbidities and recovery.

We acknowledge some limitations of the present study.

First, it was limited by its retrospective and nonrandomized design. Second, due to the limited sample size, patients with different ASIA grades were not analyzed separately. Next, the speed of deterioration of spinal cord function was not taken into account because of its retrospective nature. However, this study provides essential information regarding surgery timing for patients with incomplete paraplegia caused by MSCC.

In conclusion, this study showed that delay surgery was common in incomplete paraplegia patients with MSCC. Patients with AIS B and C who underwent surgery within 7 days had better AIS improvement.

\section{Code Availability}

IBM SPSS Statistics 25 (IBM Corporation, Armonk, NY.).

\section{Data Sharing Statement}

All patient's data was maintained with confidentiality. The data that support the findings of this study are available on request from the corresponding author. The data are not publicly available due to privacy or ethical restrictions.

\section{Ethical Approval}

This retrospective study involving human participants was in accordance with the ethical standards of the institutional and national research committee and with the 1964 Helsinki Declaration and its later amendments or comparable ethical standards. The local Ethics Committee of Peking University First Hospital approved this study (2017[1417]).

\section{Consent to Participate}

According to the local institutional review board, for this type of retrospective study, informed consent is not required.

\section{Author Contributions}

All authors made a significant contribution to the work reported, whether that is in the conception, study design, execution, acquisition of data, analysis and interpretation, or in all these areas; took part in drafting, revising or critically reviewing the article; gave final approval of the version to be published; have agreed on the journal to which the article has been submitted; and agree to be accountable for all aspects of the work.

\section{Funding}

This study was supported by the Opening Foundation of State key laboratory of molecular developmental biology (NO. 2021-MDB-KF-20).

\section{Disclosure}

The authors declare that they have no conflict of interest.

\section{References}

1. Desforges JF, Byrne TN. Spinal cord compression from epidural metastases. $N$ Engl J Med. 1992;327(9):614-619. doi:10.1056/ NEJM199208273270907

2. Siegel RL, Miller KD, Jemal A. Cancer statistics, 2019. CA Cancer J Clin. 2019;69(1):7-34. doi:10.3322/caac.21551

3. Laufer I, Rubin DG, Lis E, et al. The NOMS framework: approach to the treatment of spinal metastatic tumors. Oncologist. 2013;18 (6):744-751. doi:10.1634/theoncologist.2012-0293

4. Cofano F, Di Perna G, Zenga F, et al. The neurology-stabilityepidural compression assessment: a new score to establish the need for surgery in spinal metastases. Clin Neurol Neurosurg. 2020;195:105896. doi:10.1016/j.clineuro.2020.105896

5. Gasbarrini A, Boriani S, Capanna R, et al.; Italian Orthopaedic Society Bone Metastasis Study Group. Management of patients with metastasis to the vertebrae: recommendations from the Italian Orthopaedic Society (SIOT) Bone Metastasis Study Group. Expert Rev Anticancer Ther. 2014;14(2):143-150. doi:10.1586/14737140.2014.856532

6. La Rosa G, Conti A, Cardali S, Cacciola F, Tomasello F. Does early decompression improve neurological outcome of spinal cord injured patients? Appraisal of the literature using a meta-analytical approach. Spinal Cord. 2004;42(9):503-512. doi:10.1038/sj.sc.3101627

7. Lenehan B, Fisher CG, Vaccaro A, Fehlings M, Aarabi B, Dvorak MF. The urgency of surgical decompression in acute central cord injuries with spondylosis and without instability. Spine. 2010;35 (21SUPPL):S180-S186. doi:10.1097/BRS.0b013e3181f32a44

8. Liu YH, Hu YC, Yang XG, et al. Prognostic factors of ambulatory status for patients with metastatic spinal cord compression: a Systematic Review and Meta-Analysis. World Neurosurg. 2018;116:e278-e290. doi:10.1016/j.wneu.2018.04.188

9. Chong S, Shin SH, Yoo H, et al. Single-stage posterior decompression and stabilization for metastasis of the thoracic spine: prognostic factors for functional outcome and patients' survival. Spine J. 2012;12(12):1083-1092. doi:10.1016/j.spinee.2012.10.015

10. Park S-J, Lee C-S, Chung -S-S. Surgical results of metastatic spinal cord compression (MSCC) from non-small cell lung cancer (NSCLC): analysis of functional outcome, survival time, and complication. Spine J. 2016;16(3):322-328. doi:10.1016/j.spinee.2015.11.005

11. Fürstenberg CH, Wiedenhöfer B, Gerner HJ, Putz C. The effect of early surgical treatment on recovery in patients with metastatic compression of the spinal cord. J Bone Jt Surg Ser B. 2009;91 (2):240-244. doi:10.1302/0301-620X.91B2.20894

12. Crnalic S, Hildingsson C, Bergh A, Widmark A, Svensson O, Löfvenberg R. Early diagnosis and treatment is crucial for neurological recovery after surgery for metastatic spinal cord compression in prostate cancer. Acta Oncol (Madr). 2013;52(4):809-815. doi:10.3109/0284186X.2012.705437 
13. Quraishi NA, Rajagopal TS, Manoharan SR, Elsayed S, Edwards KL, Boszczyk BM. Effect of timing of surgery on neurological outcome and survival in metastatic spinal cord compression. Eur Spine J. 2013;22(6):1383-1388. doi:10.1007/s00586-012-2635-y

14. Chaichana KL, Woodworth GF, Sciubba DM, et al. Predictors of ambulatory function after decompressive surgery for metastatic epidural spinal cord compression. Neurosurgery. 2008;62(3):683-691. doi:10.1227/01.neu.0000317317.33365.15

15. Husband DJ. Malignant spinal cord compression: prospective study of delays in referral and treatment. Br Med J. 1998;317(7150):18-21. doi:10.1136/bmj.317.7150.18

16. Levack P, Graham J, Collie D, et al. Don't wait for a sensory level listen to the symptoms: a prospective audit of the delays in diagnosis of malignant cord compression. Clin Oncol. 2002;14(6):472-480. doi: $10.1053 /$ clon. 2002.0098

17. Oyinbo CA. Secondary injury mechanisms in traumatic spinal cord injury: a nugget of this multiply cascade. Acta Neurobiol Exp (Wars). 2011;71(2):281-299.

18. Lewin MG, Hansebout RR, Pappius HM. Chemical characteristics of traumatic spinal cord edema in cats. Effect of steroids on potassium depletion. $J$ Neurosurg. 1974;40(1):65-75. doi:10.3171/ jns.1974.40.1.0065
19. Dvorak MF, Noonan VK, Fallah N, et al. The influence of time from injury to surgery on motor recovery and length of hospital stay in acute traumatic spinal cord injury: an Observational Canadian Cohort Study. $J$ Neurotrauma. 2015;32(9):645-654. doi:10.1089/ neu.2014.3632

20. Rades D, Staackmann C, Janssen S. Predicting the ambulatory status of patients irradiated for Metastatic Spinal Cord Compression (MSCC) from head-and-neck cancer. Anticancer Res. 2018;38 (8):4833-4837. doi:10.21873/anticanres. 12794

21. Cofano F, Di Perna G, Alberti A, et al. Neurological outcomes after surgery for spinal metastases in symptomatic patients: does the type of decompression play a role? A comparison between different strategies in a 10-year experience. J Bone Oncol. 2020;26:100340. doi:10.1016/j.jbo.2020.100340

22. Yousefifard M, Rahimi-Movaghar V, Baikpour M, et al. Early versus late spinal decompression surgery in treatment of traumatic spinal cord injuries; a systematic review and meta-analysis. Emerg (Tehran, Iran). 2017;5(1):e37.

23. Bourassa-Moreau É, Mac-Thiong JM, Feldman DE, Thompson C, Parent S. Non-neurological outcomes after complete traumatic spinal cord injury: the impact of surgical timing. J Neurotrauma. 2013;30 (18):1596-1601. doi:10.1089/neu.2013.2957

\section{Publish your work in this journal}

Therapeutics and Clinical Risk Management is an international, peerreviewed journal of clinical therapeutics and risk management, focusing on concise rapid reporting of clinical studies in all therapeutic areas, outcomes, safety, and programs for the effective, safe, and sustained use of medicines. This journal is indexed on PubMed Central, CAS,
EMBase, Scopus and the Elsevier Bibliographic databases. The manuscript management system is completely online and includes a very quick and fair peer-review system, which is all easy to use. Visit http://www.dovepress.com/testimonials.php to read real quotes from published authors. 